\title{
VIEWPOINT
}

\section{Building effective critical care teams}

\author{
Constantine Manthous ${ }^{* 1}$, Ingrid M Nembhard ${ }^{2}$ and Andrea B Hollingshead ${ }^{3}$
}

\begin{abstract}
Critical care is formulated and delivered by a team. Accordingly, behavioral scientific principles relevant to teams, namely psychological safety, transactive memory and leadership, apply to critical care teams. Two experts in behavioral sciences review the impact of psychological safety, transactive memory and leadership on medical team outcomes. A clinician then applies those principles to two routine critical care paradigms: daily rounds and resuscitations. Since critical care is a team endeavor, methods to maximize teamwork should be learned and mastered by critical care team members, and especially leaders.
\end{abstract}

The fragility of critically ill patients leaves little margin for mismanagement. To offer these most vulnerable patients the greatest chance of high-quality survival, all members of the care team must 'know their stuff' and administer their crafts in a complex, coordinated fashion. World Cup champions survive the tournament through teamwork. Since the 'unit of administration' in critical care units is not the physician but rather 'the team', it is reasonable to assume that team dynamics impact outcomes as much - or more - in medicine. However, simply employing a team-based structure in a critical care unit does not ensure improved patient outcomes. We here explore three behavioral science concepts - psychological safety, transactive memory and leadership - that have been positively associated with team performance in previous research. They are harnessed daily - often unconsciously - in most critical care teams, and can be fortified to enhance care. We then show how these principles apply and can be cultivated in routine, day-today activities of the critical care team.

*Correspondence: pcmant@bpthosp.org

'Bridgeport Hospital and Yale University School of Medicine, 267 Grant Street, Bridgeport, CT 06610, USA

Full list of author information is available at the end of the article

\section{Lessons from team science}

\section{Lesson 1: cultivate psychological safety}

Research conducted in health care and other settings indicates that psychological safety plays a central role in whether expertise diversity, status differences, and temporary membership - all of which are attributes of health care teams - facilitate or hinder team effectiveness. Psychological safety refers to the degree to which individuals perceive their work environment as supportive of interpersonally risky behavior, such as asking questions, seeking help, reporting mistakes, raising concerns, or offering suggestions [1]. Individuals can perceive that engaging in these behaviors, which is necessary for team effectiveness, elevates the risk of being seen as ignorant, incompetent, disruptive or negative [2]. This risk is minimal in psychologically safe teams; their members believe that they will not suffer punishment, embarrassment, or any form of negative consequence as a result of engaging in these behaviors [3].

Research shows that health professionals often feel psychologically unsafe [4-8]. A series of studies conducted in a variety of hospital units found that only $55 \%$ of staff feel comfortable speaking up even when they perceived a problem with patient care [5-7]. The sense of psychological safety mirrors the professional hierarchy. A study of over 1,400 health professionals from 23 neonatal intensive care units found that physicians felt significantly greater psychological safety than nurses, who felt safer than respiratory therapists [8]. The latter (nonphysicians) reported that it was more difficult to bring up problems and tough issues. A national study of health professionals found that non-physicians do not speak up with concerns because they fear blame, retaliation, punishment, and belittling response [9]. Between 30\% and $50 \%$ of nurses report that nurse input is not wellreceived in their units $[6,7]$.

Studies have shown that patients treated in settings in which staff feel psychologically unsafe often experience adverse events [9-11]. For example, a cross-sectional study of the relationship between hospital climate and clinical performance showed that hospitals in which staff reported greater fear of shame and blame had significantly greater risk of 12 patient safety indicators established by the Agency for Healthcare Research and Quality [11]. 
Team and organizational research indicates that poor performance occurs because professionals in psychologically unsafe teams are less likely to engage in behaviors that contribute to team effectiveness [12]. First, they do not speak up with concerns and suggestions, which is critical for coordinating efforts, rectifying errors, and improving processes [13,14]. For example, Edmondson [4] found that nurses in psychologically unsafe units spoke up less about medication errors. Less knowledgesharing in psychologically unsafe places has been found in a variety of organizational settings, ranging from restaurant chains to web services to aircraft component manufacturing [15].

Second, individuals in psychologically unsafe teams engage less in team learning [1]. Learning is critical to team effectiveness, particularly in contexts such as health care where teams constantly implement new practices. A series of follow-up studies on the aforementioned 23 neonatal intensive care units showed that units with higher psychological safety used significantly more learning activities (for example, dry runs). In turn, they also experienced more successful implementation of new practices and $18 \%$ lower patient mortality after 2 years $[16,17]$.

Lastly, studies have also shown that psychological safety predicts problem-solving, another contributor to team effectiveness. A study of 37 (intensive care, medical/ surgical, and maternity) units in 14 hospitals showed that nurses in more psychologically safe units were more likely to participate in efforts to help solve systemic problems [18]. Likewise, in such units, there were less workarounds [19].

\section{Lesson 2: enable the development of transactive memory}

Experienced teams often solve problems better than newly formed teams [20]. One explanation for why team performance improves over time is that experienced teams often develop a transactive memory system that enables them to make better use of each individual's knowledge, skills and abilities [21].

A transactive memory system is a group-level memory system that often develops in close relationships and work teams. It involves the division of knowledge responsibilities among team members with respect to the encoding, storage, retrieval and communication of information from different knowledge areas and a shared awareness among team members of 'who knows what' and 'who will do what' [22]. A useful metaphor for describing transactive memory is a set of networked computers each containing different information but with a common directory [23]. The division of responsibilities among members of critical care teams are likely to reflect formal roles such as 'physician' or 'nurse' but others may relate to team member's unique skills and experiences.
For example, one member of the team may be especially good at calming family members while another may be especially good at finding a good vein for an IV. Accurate and shared knowledge about each member's roles and responsibilities on the team often translates into more effective communication processes: members know who to ask, what to ask, when to ask, and how to ask for information from others in the system, and they can anticipate when and how to communicate information effectively to those who need it [24].

Team behaviors associated with a well-developed transactive memory include: specialization, credibility, and task coordination [25]. As team members gain an understanding of one another's skills and expertise, they develop knowledge that is different but complementary (specialization). However, this occurs only if they trust in their teammates' expertise (credibility). Task coordination (ability of team members to coordinate their work efficiently) occurs as members develop high levels of specialization and credibility leading to high team performance.

One necessary condition for transactive memory development is cognitive interdependence: individuals must perceive that their outcomes are dependent on the knowledge of others, and those others' outcomes are dependent on their knowledge [26]. This provides the motivation for team members to attend to what others can potentially contribute to the team. Cognitive interdependence can be instilled in teams in a number of ways: through team simulations and team training, teambased rewards and the development of positive work relationships. Informal interactions and shared experiences through daily rounds provide opportunities for members to learn about the relative expertise of other members, to coordinate who does what, to observe members' skills in action, and to build positive relationships. Those systems set up by formal design (such as a listing of staff responsibilities or procedures in an ICU training manual) are either validated or modified over time as the team discovers whether individuals assigned to specific roles are capable and willing to perform them [27].

It takes time to develop a well functioning transactive memory system. Physicians in newly formed medical teams may not always know what information is needed by other team members. In a simulation of emergency medical diagnosis, twenty teams of either two or three physicians who had never worked together performed a patient handoff using a human patient simulator. In most of these teams, the physician who held the patient's chart did not read the earlier diagnosis, and did not talk to the room. As a result, many teams made the incorrect diagnosis because the physician with the chart did not understand the information needs and roles of other team members [28]. 
A primary supposition of the increasing use of simulation training for complex medical tasks/teams, including critical care resuscitation, asserts that transactive memory is an essential component of building highly performing teams. Although there are no systematic studies conducted in critical care that have compared the performance of new and experienced teams, Hunziker and colleagues [29] examined 50 teams that performed cardiopulmonary resuscitation simulation exercises. Teams that included members who had not worked together before provided less hands-on care and later initial shocks compared to teams that had trained together before exercises [29].

Transactive memory is not just important for team performance but it also boosts team morale and commitment. Michinov and colleagues [30] conducted a crosssectional study of 193 nurses and anesthetists from eight French hospitals. The survey contained measures of transactive memory, work-team effectiveness and work attitudes. The researchers found that transactive memory positively predicted members' perceptions of team effectiveness and also affective outcomes such as team identification and job satisfaction.

Although studies of team transactive memory in organizations have focused on the benefits of member specialization, building in a certain degree of overlapping knowledge so that members can substitute for one another as necessary may be especially important for critical care teams where team membership changes on a daily basis and non-routine, time-sensitive, life-threatening decisions are commonplace.

\section{Lesson 3: leaders' behavior matters}

Team leader behavior is a well-documented contributor to team effectiveness [31]. How team leaders structure the team, define its purpose, remove organizational barriers, help individual members enhance their contributions to the team, and coach to help members use their collective resources to fulfill team goals all influence team success [32]. Additionally, team leaders are influential on an interpersonal level because their behavior is salient to team members. Members look to leaders' behaviors as an indicator of what is expected and accepted of their own behavior [33]. Thus, leader behavior shapes team climate and team capabilities. With respect to team climate, for example, research shows that leader inclusiveness - the extent to which leaders, such as physicians or nurse managers, sought and appreciated others' input, made themselves available, and displayed fallibility - predicts psychological safety. In fact, research has found that the difference in psychological safety between physicians and non-physicians is minimized in health care teams with empowering leadership [8]. In these units, psychological safety is high, as is team learning and performance [12].
Leaders who adopt an empowering leadership style share power and give more autonomy to subordinates [34]. Some of the behaviors associated with an empowering leadership style include: leading by example, informing, coaching, participative decision making and showing concern for the team [35]. In studies of management teams in a variety of organizations, an empowering leadership style has been positively associated with knowledge sharing and higher levels of team efficacy, which in turn are positively associated with team performance [36]. Empowering leadership styles have also been associated with the job satisfaction of subordinates [15]. It is important to note that many of these studies were conducted in management teams where teams were not making life and death decisions. Research on trauma resuscitation teams suggests that there may be other important contingencies for critical care teams.

Yun and colleagues [37] observed admissions, shadowed teams, and interviewed specialists in an ethnographic study of trauma resuscitation teams over a six-month period. Their findings demonstrated that the effectiveness of different leadership styles depended on the severity of the patient's condition and the level of team experience. Directive leadership was more effective when a patient was severely injured, whereas empowering leadership was more effective when a patient was not severely injured. Directive leadership was also better when a trauma team was inexperienced, but empowering leadership was better when a trauma team had high experience working together.

Although it has not been addressed in previous studies, it is quite possible that empowering leadership during patient rounds, quality improvement meetings and other routine low-stakes situations may enable critical care teams to coordinate more effectively during traumas under directive leadership. The psychological safety that develops through empowering leadership may increase the likelihood that team members will notice and speak up if they see a physician making an error during a resuscitation [38].

\section{A clinician's synthesis}

All critical care is 'high stakes'; survival and its quality depend upon optimal implementation of high-quality decisions. Some decisions can be made more deliberatively, and if errant, there is opportunity for reversibility, whereas others may cause immediate irreversible endorgan dysfunction or death. Daily rounds and bedside resuscitations are common team activities that demonstrate how intra-team relationships can be activityspecific yet highly complementary. The importance of leadership, psychological safety and transactive memory in team effectiveness becomes self-evident if we dissect these everyday activities. 
High-stakes, time-to-ponder: daily care and 'unit management'

A week after finishing fellowship, I walked into 'my' ICU at a 350-bed teaching hospital. I was the unit's first intensivist, team cohesion was poor and mortality was $34 \%$ for patients whose expected mortality was $24 \%$ [39]. While I had exemplary role models, my critical care fellowship provided no formal instruction on how to lead, organize and motivate teams. Consequently, the first decade was marked by trial and (frequent) error; but I believed that the excess mortality justified 'transformation by brute force.' Despite the fact that patient outcomes improved, the first year was harrowing for my teammates. The directive style that had served me well in sports antagonized team members. Nurses and residents cried. Everyone complained. Change is 'hard, even when implemented through gradual consensus-building, and there are easy ways and hard ways to achieve healthcare goals. I had to 'stumble onto' how to facilitate team performance.

Interdisciplinary rounds are the foundation of critical care. Stakes of the discussions and decisions are high, but there is ample time to build team skills and empowerment. I mistakenly treated other team members as 'reporters', there to provide me with information so I could make most of the decisions. While this (immature) modus operandi may be expected from a just-graduated trainee, eager to assert his new skills and directive discretion, it simultaneously disrespects and fails to leverage the talents and energies of teammates. The intensivist can not be at every bedside, every minute. She depends highly on others (especially nurses and physician extenders) to keep her apprised of substantial developments as they unfold. It is in the ICU leader's and patients' interests to have teammates who: are well trained, to distinguish between substantive versus irrelevant signal; have learned how to administer the multitude of daily, evidence-based therapies (automatically) without constant oversight and reteaching; and feel safe, empowered and prepared to speak up - during rounds or subsequently - when they see something that has not been reported to the team that they think may impact (the team's collective synthesis and thus) individual care plans or systems safety.

Strong leaders can, but they do not need to, dominate team discourse. Consensual leadership cultivates psychological safety, which in turn promotes positive transactive memories. Team rounds take a bit longer, but time is well invested because both routine and emergency care are positively impacted (see below). A number of concrete 'leadership practices', exercised during rounds, help achieve these goals.

First, leaders should actively illicit the observations and viewpoints of others on the team (even when he thinks he knows the answer). Historic hierarchies discourage non-doctors and/or junior team members from speaking up. If a patient's bedside nurse has failed to share his/her observations or suggestions, simply ask: 'Have we missed anything?' This technique simultaneously provides psychological safety by transmitting to the individual, and all team members, that their observations/opinions are welcome ... or even expected. Transactive memory is formed that 'my perspective' matters - and so in future rounds (and emergencies; see below), non-physician team members feel more comfortable contributing their - often critical - observations.

Teaching is another important technique of promoting team spirit and psychological safety. Healthcare professionals share a heritage of self-improvement as a means to reduce human suffering. By promoting a team culture of shared inquiry and intellectual discovery, the leader demonstrates beneficence; genuine interest in the growth of teammates. Teaching must not be unilateral didacticism. All team members can be encouraged to bring their latest learning to the team for consideration. Meritorious ideas should be implemented, thereby demonstrating that good ideas (not just those of the team leader) will receive consideration and can be actualized. By cultivating rounds as a shared time/space for group learning, the democratic leader builds psychological safety and transactive memory. Both the team's interpersonal modus operandi and its ever-increasing library of shared learning and practices eventually become 'traits' - hard-wired, unconsciously, into daily activities.

Another powerful technique is to regularly name team victories and failures. Open, non-accusatory discussion of failures and errors permits us to share the negative emotions that can otherwise erode spirit and effectiveness. A particularly powerful tool is for the team-leader to choose his own mistakes - acknowledging fallibility, providing the 'safety' for others to do the same. By acknowledging that errors are part of human being, and that the only inexcusable sin is to not learn collectively from our errors, guilt can be neutralized or even 'spun' into positive experiences that cultivate willingness to selfreport for systems-improvement in the future (that is, positive transactive memory). Similarly, team victories can be named and shared. When a patient, not expected to live, leaves the hospital on a path to recovery, it is not the intensivist's victory but rather the result of the team's collective effort and energy. In medical ICUs, one in five patients do not leave hospital alive, and a sizeable proportion of the remainder experience suboptimal survivorship. So it is particularly important for the team not to get discouraged, to collectively celebrate the team's promotion of 'good saves' and 'good deaths'.

Team science concepts apply equally to monthly quality assurance meetings. Representatives from each group of 
professionals bring concerns or new practices for consideration by the group. If consensus builds that an item requires action, processes are deconstructed and reconstructed to address the problem or install a solution. Each team member brings a different point of view to inform process engineering, champion implementation and monitor solutions.

\section{Ultra-high stakes, no-time-to-ponder; cardiopulmonary resuscitation}

On Thanksgiving Day, a young man with variceal hemorrhage was banded shortly after admission, but soon a river of blood poured from his intubated mouth. In the ensuing 2 hours, three nurses, a respiratory therapist, gastroenterologist, three residents, one fellow and I moved reflexively and simultaneously. Participating nurses' assignments were cross-covered, saline was squeezed by residents with the largest triceps, another central line was placed, another quick endoscopy failed, blood and body warmers were fetched and applied. Blood products were fetched and administered, and finally a Blakemore tube was placed. 'Thinking aloud' throughout, we shared ideas and modified the approach several times as the situation evolved. Roughly 10 units of packed cells, 5 fresh frozen plasma, 3 platelets, $10 \mathrm{~L}$ normal saline and 24 hours later, he was stable and not one organ system had failed. The Blakemore was deflated, repeat banding was successful, he was extubated and went home shortly thereafter. That Thanksgiving Day, without congas or fanfare, our team played 'the beautiful game'.

Each member's individual training and excellence, coupled with our team's transactive memory and psychological safety (to offer opinions that differed from mine), resulted in an optimal outcome, where he could have died that same day. Transactive memory from daily rounds and previous resuscitations were the predicate for both the coordination of efforts (that is, knowing what to do, feeling comfortable acting independently even before an order was issued) and the real-time clinical problem solving (that is, everyone in the room felt safe to speak up and offer opinions about what to do next based on accumulated, pooled experience of the team). Note that my role necessarily became more directive than during rounds - teams expect a resuscitation leader, and deliberate democratic processes are temporarily/partly suspended. This highlights that 'contingent leadership', that is, determined by the venue or situation, is most germane to critical care. But even during emergencies and my more directive approach, nearly everyone offered suggestions that helped us synthesize and strategize. Thinking aloud in our resuscitations is a quality/safety check (in case reasoning/logic is wrong) and broadcasts to the team 'what is next', so team members can participate, prepare and better coordinate their activities.

\section{Conclusion}

There are insufficient data to prove that behavioral science can be applied to improve ICU outcomes [40,41]. Nonetheless, ICU management is, fundamentally, teambuilding that is teachable and learnable. Educational programs might include formal training in behavioral sciences to complement young clinicians' developing repertoire of medical science. World Cups are not won by individuals, and since teams are the sharp end of the critical care stick, it is reasonable to believe that team performance impacts patient outcomes as much or more than brilliance of any one individual team member. Trainees in critical care need not struggle for a decade after training to acquire these skills by trial and error at the expense of nurses, therapists, patients and the team.

This article is part of a series on Healthcare Delivery, edited by Dr Andre Amaral and Dr Gordon Rubenfeld.

\section{Competing interests}

The authors declare that they have no competing interests.

\section{Author details}

'Bridgeport Hospital and Yale University School of Medicine, 267 Grant Street, Bridgeport, CT 06610, USA. ${ }^{2}$ Yale University, School of Public Health and School of Management, 60 College Street, \#308, P.O. Box 208034, New Haven, CT 06520-8034 USA. ${ }^{3}$ Annenberg School of Communication and Journalism, University of Southern California, Los Angeles, CA 90089-0281, USA.

Published: 12 August 2011

\section{References}

1. Edmondson AC: Psychological safety and learning behavior in work teams. Administrative Sci Quart 1999, 44:350-383.

2. Edmondson AC: Managing the risk of learning: Psychological safety in work teams. In International Handbook of Organizational Teamwork and Cooperative Working. Edited by West M, Tjosvold D, Smith KG. London: John Wiley \& Sons; 2003:255-276.

3. Kahn WA: Psychological conditions of personal engagement and disengagement at work. Acad Management J 1990, 33:692-724

4. Edmondson AC: Learning from mistakes is easier said than done: Group and organizational influences on the detection and correction of human error. J Appl Behavioral Sci 2004, 32:5.

5. Thomas E, Sexton J, Helmreich R: Discrepant attitudes about teamwork among critical care nurses and physicians. Crit Care Med 2003, 31:956-959.

6. Sexton JB, Makary MA, Tersigni AR, Pryor D, Hendrich A, Thomas EJ, Holzmueller CG, Knight AP, Wu Y, Pronovost PJ: Teamwork in the operating room: Frontline perspectives among hospitals and operating room personnel. Anesthesiology 2006, 105:877-884.

7. Sexton JB, Holzmueller CG, Pronovost PJ, Thomas EJ, MCFerran S, Nunes J, Thompson DA, Knight AP, Penning DH, Fox HE: Variation in caregiver perceptions of teamwork climate in labor and delivery units. J Perinatol 2006, 26:463-470.

8. Nembhard IM, Edmondson AC: Making it safe: The effects of leader inclusiveness and professional status on psychological safety and improvement efforts in health care teams. J Organizational Behavior 2006, 27:941-966.

9. Maxfield D, Grenny J, McMillan R, Patterson K, Switzler A: Silence Kills: The Seven Crucial Conversations for Healthcare. Provo, UT: VitalSmarts, LC; 2005.

10. Rathert C, Ishqaidef G, May DR: Improving work environments in health care: Test of a theoretical framework. Health Care Management Rev 2009, 34:334-343.

11. Singer S, Lin S, Falwell A, Gaba D, Baker L: Relationship of safety climate and safety performance in hospitals. Health Services Res 2009, 44:399-421. 
12. Nembhard IM, Edmondson AC: Psychological safety: A foundation for speaking up, collaboration and experimentation. In The Oxford Handbook of Positive Organizational Scholarship. Edited by Cameron K, Spreitzer G. Oxford: Oxford University Press; in press.

13. Detert JR, Burris ER: Leadership behavior and employee voice: Is the door really open? Acad Management J 2007, 50:869-884.

14. Siemsen E, Roth AV, Balasubramanian S, Anand G: The influence of psychological safety and confidence in knowledge on employee knowledge sharing. Manufacturing Service Operations Management 2009, 11:429-447.

15. Siemsen $E$, Roth AV, Balasubramanian S, Anand G: The influence of psychological safety and confidence in knowledge on employee knowledge sharing. Manufacturing Service Operations Management 2009, 11:429-447.

16. Tucker AL, Nembhard IM, Edmondson AC: Implementing new practices: An empirical study of organizational learning in hospital intensive care units. Management Sci 2007, 53:894-907.

17. Nembhard IM, Tucker AL: Deliberate learning to improve performance in dynamic service settings: Evidence from hospital intensive care units. Organization Sci 2010. Published online ahead of print September 15, 2010, pp. 1-16.

18. Tucker AL: An empirical study of system improvement by frontline employees in hospital units. Manufacturing Service Operations Management 2007, 9:492-505.

19. Halbesleben JRB, Rathert C: The role of continuous quality improvement and psychological safety in predicting work-arounds. Health Care Management Rev 2008, 33:134-144.

20. Hollingshead AB, Gupta N, Yoon K, Brandon DP: Transactive memory theory and teams: Past, present, and future. In Theories of Team Cognition: Crossdisciplinary Perspectives. Edited by Salas E, Fiore SM, Letsky M. New York: Taylor \& Francis: 2011:421-455.

21. Moreland RL: Transactive memory: Learning who knows what in work groups and organizations. In Sharing Knowledge in Organizations. Edited by Thompson L, Messick D, Levine J. Hillsdale, NJ: Lawrence Erlbaum; 1999:3-31.

22. Hollingshead AB: Transactive memory. In Encyclopedia of Group Processes and Intergroup Relations. Edited by Levine J, Hogg M. Thousand Oaks, CA: Sage; 2009:931-933.

23. Wegner DM: A computer network model of human transactive memory. Social Cognition 1995 13:319-339.

24. Hollingshead AB, Brandon DP: Potential benefits of communication in transactive memory systems. Hum Commun Res 2003, 29:607-615.

25 Lewis K. Measuring transactive memory systems in the field: Scale development and validation. J Appl Psychol 2003, 88:587-604.

26. Hollingshead AB: Cognitive interdependence and convergent expectations in transactive memory. J Personality Social Psychol 2001, 81:1080-1089.

27. Brandon DP, Hollingshead AB: Transactive memory systems in organizations: Matching tasks, expertise, and people. Organization SC 2003, 15:633-644
28. Tschan F, Semmer NK, Gurtner A, Bizzari L, Spychiger M, Breuer M, Marsch SU: Explicit reasoning, confirmation bias, and illusory transactive memory: A simulation study of group medical decision making. Small Group Res 2009, 40:271-300

29. Hunziker S, Tschan F, Semmer NK, Zobrist R, Spychiger M, Breuer M, Hunzike $\mathrm{PR}$, Marsch SC: Hands-on time during cardiopulmonary resuscitation is affected by the process of teambuilding: a prospective randomized simulator-based trial. BMC Emerg Med 2009, 9:3

30. Michinov E, Olivier-Chiron E, Rusch E, Chiron B: Influence of transactive memory on perceived performance, job satisfaction and identification in anaesthesia team. Br J Anaesth 2008, 100:327-332.

31. Hogan R, Curphy GJ, Hogan J: What we know about leadership. Am Psychol 1994, 49:493-504

32. Hackman JR, Wageman R: A theory on team coaching. Acad Management Rev 2005, 30:269-287.

33. Tyler TR, Lind EA: A relational model of authority in groups. Adv Exp Psychol 1992, 25:115-191.

34. Srivastava A, Bartol KM, Locke EA: Empowering leadership in management teams: effects on knowledge sharing, efficacy, and performance. Acad Management J 2006, 49:1239-1251.

35. Arnold JA, Arad S, Rhoades JA, Drasgow F: The empowering leadership questionnaire: The construction and validation of a new scale for measuring leader behaviors. J Organizational Behavior 2000, 21:249-269.

36. Morrison R, Jones L, Fuller B: The relation between leadership style and empowerment on job satisfaction of nurses. J Nursing Admin 1997 27:27-34.

37. Yun S, Faraj S, Xiao Y, Sims H: Team leadership and coordination in trauma resuscitation. In Advances in Interdisciplinary Studies of Work Teams. Volume 9 Edited by Beyerlein M. Bingley, UK: Emerald Group Publishing Limited; 2003:189-214

38. Gupta N, Hollingshead AB: Differentiated versus integrative transactive memory effectiveness: It depends on the task. Group Dynamics 2010, 14:384-398.

39. Manthous CA, Amoateng-Adjepong Y, al-Kharrat T, Jacob B, Alnuaimat HM, Chatila W, Hall JB: Effects of a medical intensivist on patient care in a community teaching hospital. Mayo Clin Proc 1997, 72:391-399.

40. Shortell SM, Zimmerman JE, Rousseau DM, Gillies RR, Wagner DP, Draper EA, Knaus WA, Duffy J: The performance of intensive care units: Does good management make a difference? Med Care 1994, 32:508-525.

41. Manthous CA, Hollingshead AB: Team science and critical care. Am J Respir Crit Care Med 2011 [Epub ahead of print]

doi:10.1186/cc10255

Cite this article as: Manthous C, et al:: Building effective critical care teams. Critical Care 2011, 15:307. 